Article

\title{
Bioactive Flavonoids from the Stem Bark of Cordia dichotoma Forst.: Identification, Docking and ADMET Studies
}

\author{
Nazim Hussain ${ }^{1^{*}}$, Bibhuti Bhushan Kakoti ${ }^{2}$, Mithun Rudrapa $3^{{ }^{*}}$, Khomendra Kumar Sarwa ${ }^{4}$, Ismail Celik ${ }^{5}$, Em- \\ manuel Ifeanyi Attah ${ }^{6}$, Shubham Jagadish Khairnar ${ }^{7}$, Soumya Bhattacharya ${ }^{8}$, and Ranjan Kumar Sahoo ${ }^{9}$
}

1 Kingston Imperial Institute of Technology and Science, Dunga, Dehradun, India; nhussain116@gmail.com

2 Department of Pharmaceutical Sciences, Dibrugarh University, Dibrugarh, Assam, India; bibhutikakoti@dibru.ac.in

3 Rasiklal M. Dhariwal Institute of Pharmaceutical Education \& Research, Pune, Maharashtra, India; rsmrpal@gmail.com

4 Department of Pharmacy, Govt. Girls' Polytechnic, Raipur, Chhattisgarh, India; khomendra.sarwa@gmail.com

5 Department of Pharmaceutical Chemistry, Faculty of Pharmacy, Erciyes University, Kayseri, Turkey; celikismail66@gmail.com

6 Department of Pharmaceutical and Medicinal Chemistry, University of Nigeria, Nsukka, Nigeria; emmanuel.attah.pg00429@unn.edu.ng

7 MET Institute of Pharmacy, Bhujbal Knowledge City, Nashik, Maharashtra, India; sunnykhairnar62@gmail.com

8 Guru Nanak Institute of Pharmaceutical Science and Technology, Kolkata, India; soumya.bhattacharya@gnipst.ac.in

9 School of Pharmacy and Life Sciences, Centurion University of Technology and Management, Bhubaneswar, Odisha, India; ranjankumar.sahoo@cutm.ac.in

*Correspondence: rsmrpal@gmail.com; nhussain116@gmail.com; Tel.: 91-8638724949

\begin{abstract}
Cordia dichotoma Forst. (F. Boraginaceae) has been traditionally used for the management of a variety of human ailments. In our earlier work, the antidiabetic activity of methanolic bark extract of C. dichotoma (MECD) has been reported. In this paper, two flavonoid molecules were isolated (by column chromatography) and identified (by IR, NMR and Mass spectroscopy/spectrometry) from the MECD with an aim to investigate their antidiabetic effectiveness. Molecular docking and ADMET studies were carried out using AutoDock Vina software and Swiss ADME online tool, respectively. The isolated flavonoids were identified as 3,5,7,3', $4^{\prime}$-tetrahydroxy-4-methoxyflavanone-3-O-L-rhamnopyranoside and 5,7,3'-trihydroxy-4-methoxyflavanone-7-O-L-rhamnopyranoside (quercitrin). Docking and ADMET studies revealed the promising binding affinity of flavonoid molecules for human lysosomal alpha-glucosidase and human pancreatic alpha-amylase with acceptable ADMET properties. Based on computational studies, our study reports the antidiabetic potential of the isolated flavonoids with predictive pharmacokinetics profile.
\end{abstract}

Keywords: C. dichotoma; Flavonoids; Antidiabetic; alpha-glucosidase, alpha-amylase, Docking; ADMET

\section{Introduction}

Cordia dichotoma Forst. (also known as Indian cherry, F. Boraginaceae) is a traditionally important deciduous medicinal plant widely grown in India, Sri Lanka and other tropical countries of the world [1]. This plant has been traditionally (Ayurveda, Unani and Siddha medicines) used for the management of a variety of human ailments/ disorders [1]. Leaves and stem bark have been used traditionally in the treatment of fever, dyspepsia, diarrhea, leprosy, gonorrhoea and wounds [2]. Leaves, seeds, bark and 
fruits have been reported to exhibit anti-inflammatory, anthelmintic, antibacterial, antileprotic, antiviral, diuretic, astringent, demulcent, laxative/purgative, expectorant/ antitussive, tonic, immunomodulatory, hepatoprotective, and gastroprotective/ antiulcer activities $[3,4]$.

Recent literature have also reported the anti-inflammatory [3], antidiabetic [4], anticancer [2], and antioxidant [3] activities for the bark extract of C. dichotoma. Phytoconstituents

like

3',5-dihydroxy-4'-methoxyflavanone-7-O-alpha-L-rhamnopyranoside,

$\beta$-sitosteryl-3 $\beta$-glucopyranoside-6'-O-palmitate, quercitrin, $\beta$-sitosterol have already been isolated from the leaves of this plant [5]. Betulin, lupeol-3-rhamnoside, $\beta$-sitosterol, taxifolin-3-5-dirhamnoside, hesperitin-7-rhamnoside, rutin, chlorogenic acid and caffeic acid have been reported from seeds of $C$. dichotoma [2-5]. Flavonoids, the most important class of plant polyphenolics possessing diverse range of biological/ pharmacological potential [6-8], are attributed to be the most dominant phytochemical components in various plant parts of $C$. dichotoma. In this work, the isolation and identification of bioactive flavonoids from the methanolic bark extract of $\mathrm{C}$. dichotoma Forst was carried out. The isolated flavonoid molecules were further investigated for their antidiabetic potential and pharmacokinetic properties by molecular docking and ADMET studies.

\section{Results and Discussion}

The phytochemical analysis revealed the presence of flavonoids, alkaloids, glycosides, saponins, steroids, carbohydrates and proteins in the methanolic bark extract of C. dichotoma Forst (MECD).

\subsection{Identification of isolated phytocompounds}

\subsubsection{Compound 1 (MECD-1)}

Subfraction 20-78 was purified by column chromatography on silica using methanol:ethyl acetoacetate to yield the pure compound 1 (120 mg). The isolated compound 1 was obtained as pale yellow amorphous powder with a melting range of 163-165 ${ }^{\circ} \mathrm{C}$. The structure of the isolated compound 1, represented in Figure 1, was elucidated by UV, IR, 1HNMR, 13CNMR and Mass spectroscopic/spectrometric analyses.

UV ( $\lambda$ max, nm, MeOH): 307, 334; FT-IR ( $\left.v_{\max }, \mathrm{cm}-1, \mathrm{KBR}\right): 3265,2960,2895,1668$, 1616, 1429, 1367; 1HNMR ( $\delta$, 400 MHz, DMSO-d6): 0.79 (J=6.0 Hz), 3.98 (J=15.0, 3.5 Hz), 2.96 (J=15.0,11.0Hz), 3.02 (J=11.0, $3.5 \mathrm{~Hz}), 4.41,4.43,5.25,6.21,6.42(\mathrm{~J}=2.0 \mathrm{~Hz}), 7.26$ (J=6.5, 2.0 Hz); 13CNMR (ס, $100 \mathrm{MHz}$, DMSO-d6): 193.56, 102.25, 55.78, 52.55 .

The IR bands at $3265 \mathrm{~cm}-1$ (O-H stretching) revealed the presence of hydroxyl group in the structure of compound 1. Other prominent absorption bands at 2960 and $2895 \mathrm{~cm}^{-1}$ (aliphatic C-H stretching), $1668 \mathrm{~cm}^{-1}$ (C=O stretching) and $1616 \mathrm{~cm}^{-1}$ (aromatic $\mathrm{C}=\mathrm{H}$ stretching) indicated the presence of methyl group $\left(\mathrm{CH}_{3}\right), \alpha, \beta$ unsaturated carbonyl group, and aromatic rings. In 1HNMR spectrum, three one-proton double doublets at $\delta$ $3.98(\mathrm{~J}=15.0,3.5 \mathrm{~Hz}), 3.02(\mathrm{~J}=11.0,3.5 \mathrm{~Hz})$ and $2.96(\mathrm{~J}=15.0,11.0 \mathrm{~Hz})$ were ascribed to H-2, $\mathrm{H}-3 \alpha$ and $\mathrm{H}-3 \beta$ protons, respectively of ring $\mathrm{C}$ of a flavonone moiety. Two one-proton doublets at $\delta 6.21$ and $6.42(\mathrm{~J}=2.0 \mathrm{~Hz}$,each) were assigned to $\mathrm{H}-6$ and $\mathrm{H}-8$ aromatic protons. Two doublets at $\delta 7.26(\mathrm{~J}=6.5,2.0 \mathrm{~Hz})$, each integrating for one proton, were ascribed correspondingly to $\mathrm{H}-2, \mathrm{H}-5$ and $\mathrm{H}-6$ of aromatic protons. A three-protons inglet at $\delta 3.61$ was attributed to methoxy $(\mathrm{OCH} 3)$ protons. A broad singlet at $\delta 5.25$ was accounted to H-1" anomeric proton, while a three proton doublet at $\delta \quad 0.79(\mathrm{~J}=6.0 \mathrm{~Hz})$ was appeared due to secondary methyl proton $\mathrm{H}-6$ " of rhamnose unit. The remaining 
protons of sugar unit appeared between $\delta 4.43$ and 4.41. The 13CNMR spectra showed twenty two distinct signals suggesting that the compound contains twenty two carbon atoms. The important signals appeared at $\delta 193.56$ (C-4, carbony carbon), 102.25 (C-1 anomeric carbon), 55.78 (methoxy carbon OMe), and 17.95 (C-6" methyl carbon). The presence of an aromatic methoxy group was confirmed by position of the methyl signal at $\delta 52.55$. The molecular ion [M]+ peak was obtained at $m / z 446.0$ which concord the molecular formula of the compound 1 as $\mathrm{C}_{22} \mathrm{H}_{22} \mathrm{O}_{11}$. The NMR spectral data also supported the structure of the compound. A thorough spectral interpretation suggests that the compound 1 (MECD-1) is 5,7,3'-trihydroxy-4-methoxyflavanone-7-O-L-rhamnopyranoside.<smiles>COc1ccc(-c2cc(=O)c3c(O)cc(OC4OC(C)C(O)C(O)C4O)cc3o2)cc1O</smiles>

Figure 1. Structure of compound 1 (MECD-1)

\subsubsection{Compound 2 (MECD-2)}

Subfraction 120-184 was purified by column chromatography on silica gel using methanol:ethyl acetoacetate to obtain the pure compound 1 (160 mg). The isolated comppund 1 was obtained as pale yellow crystalline powder with a melting range of 176-178 ${ }^{\circ} \mathrm{C}$. The structure of the isolated compound 1, represented in Figure 2 was elucidated by UV, IR, 1HNMR, 13CNMR and Mass spectroscopic/spectrometric analyses.

UV ( $\lambda$ max, nm, MeOH): 312, 346; FT-IR ( $\left.v_{\max } \mathrm{cm}^{-1}, \mathrm{KBR}\right): 3265,2950,2880,1654$, 1502, 1454, 1354, 810. ${ }^{1} \mathrm{HNMR}$ ( $\delta, 400 \mathrm{MHz}$, DMSO-d $)$ ): 0.73 (J=7.1Hz), 3.96-4.81, 6.11, 6.29 $(\mathrm{J}=2.1 \mathrm{~Hz}), 6.78$ (J=9.6 Hz), 7.14 (J=9.6, $2.2 \mathrm{~Hz}), 7.20$ (J=2.2 Hz), 12.55; ${ }^{13} \mathrm{CNMR}(\delta, 100 \mathrm{MHz}$, DMSO-d6): 156.90 (C-2), 134.69 (C-3), 178.20 (C-4), 104.56 (C-4), 161.75 (C-5), 99.15(C-6), 164.63 (C-7), 64.09 (C-8), 157.76(C-8), 121.22 (C-1'), 116.13 (C-2'),145.65 (C-3'), 148.88 (C-4'), 2115.93 (C-5'), 121.58 (C-6'), 102.29 (C-1"), 71.03 (C-2"), $70.83\left(\mathrm{C}-3^{\prime \prime}\right), 71.66$ (C-4"), 70.51 (C-5"), 17.95 (C-6").

The IR bands at $3265 \mathrm{~cm}^{-1}$ (O-H stretching) revealed the presence of hydroxyl group in the structure of compound 2. Other prominent absorption bands at 2950 and $2880 \mathrm{~cm}^{-1}$ (aliphatic C-H stretching), $1654 \mathrm{~cm}^{-1}\left(\mathrm{C}=\mathrm{O}\right.$ stretching) and $1502 \mathrm{~cm}^{-1}$ (aromatic $\mathrm{C}=\mathrm{H}$ stretching) indicated the presence of methyl group $\left(\mathrm{CH}_{3}\right), \alpha, \beta$ unsaturated carbonyl group, and aromatic rings. The ${ }^{1} \mathrm{HNMR}$ spectrum exhibited a set of two coupled doublets at $\delta 6.11$ and $6.29(\mathrm{~J}=2.1 \mathrm{~Hz}$, each) which was ascribed to H-6 and H-8 aromatic protons. Another set of coupled signals consisting of two doublets at $\delta 7.20(\mathrm{~J}=2.2 \mathrm{~Hz}), 6.78(\mathrm{~J}=9.6$ $\mathrm{Hz}$ ) and a double-doublet at $\delta 7.14\left(\mathrm{~J}=9.6,2.2 \mathrm{~Hz}\right.$ ) were ascribed to $\mathrm{H}-2^{\prime}, \mathrm{H}-5^{\prime}$ and H-6' aromatic protons of ring B. A doublet at $\delta 5.15(\mathrm{~J}=8.1 \mathrm{~Hz})$ was assigned to $\mathrm{H}-1{ }^{\prime \prime}$ anomeric 
proton, while as another doublet at $\delta 0.73(\mathrm{~J}=7.1 \mathrm{~Hz})$ was attributed to methyl protons (H-6") of rhamnose unit. The remaining protons of rhamnose resonated from $\delta 4.81$ to 3.96. A single proton singlet at $\delta 12.55$ was attributed to hydroxyl proton. The ${ }^{13} \mathrm{CNMR}$ spectrum displayed signals for twenty-one carbons. Important signals appeared for carbonyl carbon ( $\delta 178.20, C-4)$, anomeric carbon $(\delta 102.29, C-1 ")$, and methyl carbon $(\delta$ 17.94, C-6"). The molecular ion [M]+ peak was obtained at $m / z 448.0$ which concord the molecular formula of the compound as $\mathrm{C}_{21} \mathrm{H}_{20} \mathrm{O}_{11}$. The ${ }^{1} \mathrm{H}$ and ${ }^{13} \mathrm{C}$ NMR data was compared with other reported flavonoids and was found to be 3,5,7,3', ' $^{\prime}$-tetrahydroxy-4-methoxyflavanone-3-O-L-rhamnopyranoside (Quercitrin (Quercetin-3-O-a-L-rhamnoside).<smiles>CC1OC(Oc2c(-c3ccc(O)c(O)c3)oc3cc(O)cc(O)c3c2=O)C(O)C(O)C1O</smiles>

Figure 2. Structure of compound 2

\subsection{Molecular docking}

Molecular docking is used to understand the drug-receptor interaction, binding affinity and binding orientation of bioactive molecules into the target protein molecule. The objective behind docking study is to predict a particular biological activity based on the binding orientation/ affinity of small molecule ligands to the appropriate target active site [9]. In the docking study, the binding affinity was predicted in terms of the interaction energy ( $\mathrm{kcal} / \mathrm{mole}$ ). Results of docking (binding) energies are given in Table 1. Both the compounds exhibited very good binding affinity against both alpha-glucosidase and alpha-amylase enzyme. The compound 1 (MECD-1) exhibited more binding affinity against alpha-amylase compared to the alpha-glucosidase. On the hand, the compound 2 (MECD-2) showed better affinity against alpha-glucosidase than alpha-amylase. No much variation in binding energies between these two enzymes were observed. Overall, both the isolated flavonoids exhibited significant inhibitory potential of human glucosidase and amylase enzymes.

Table 1. Docking data of compounds 
Compound 1 (MECD-1)

\begin{tabular}{ll}
$5 \mathrm{NN} 8$ & $1 \mathrm{~B} 2 \mathrm{Y}$ \\
\hline-7.8 & -8.6 \\
-8.0 & -7.8 \\
\hline
\end{tabular}

Compound 2 (MECD-2)

5NN8: Human lysosomal acid alpha-glucosidase

1B2Y: Human pancreatic alpha-amylase

MECD: Metanolic bark extract of $C$. dichotoma

Post-docking visualization of protein-ligand complexes revealed that the compounds interacted with active site residues of the protein molecules through the formation of predominantly hydrogen bonding interactions (Figure 3 \& Figure 4). From the observation of 2D interaction diagarms of compound 1-alpha-glucosidase complexes, it is clear that compound 1 formed H-bonds with Trp59, Gln63, Asp197, Asp300 and Asp356 residues, whereas the compound 2 interacted with Tyr62, His101, His201 and Gly306 residues through H-bonds (Figure 3a, 3b). The 3D diagrams revealed the binding conformation and binding poses of the compounds at the catalytic site of alpha-glucosidase (Figure 3c, 3d) were observed.

(a)

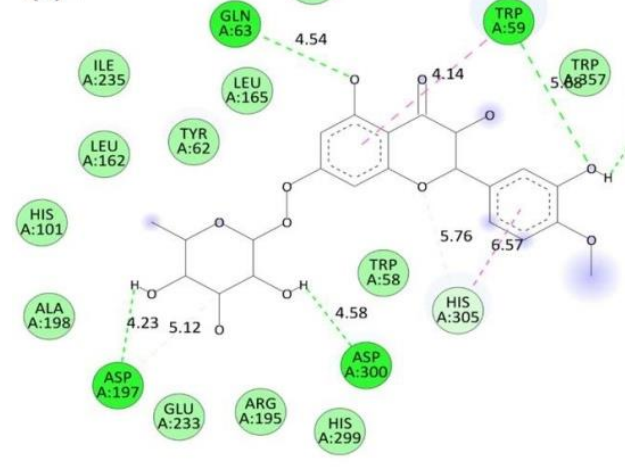

(b)

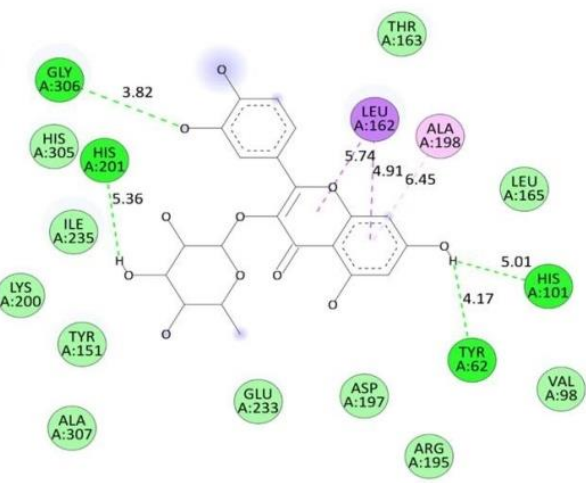

(c)

(d)
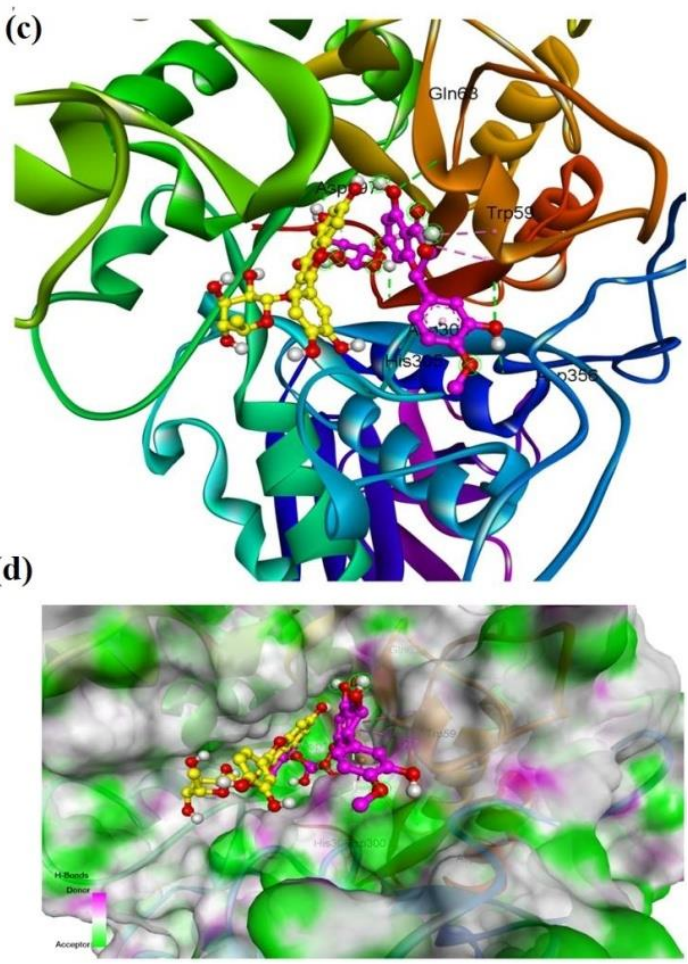

Figure 3. (a) $2 \mathrm{D}$ interactions between compound 1 and alpha-glucosidase, (b) $2 \mathrm{D}$ intercations between compound 2 and alpha-glucosidase showing hydrogen bonding and other non-covalent interactions with amino acid residues at the active site, (c) 3D representation of protein-ligand interactions showing binding conformation, (d) binding poses/ binding modes of both the compounds at the catalytic site of alpha-glucosidase.

From the observation of 2D interaction diagarms of compound 2-alpha-amylase complexes, it is clear that compound 1 formed prominent H-bonds with Asp404, Ser523, 
Ser524 residues, whereas the compound 2 interacted with Asp616, His674 and Leu678 residues through $\mathrm{H}$-bonds (Figure $4 \mathbf{a}, \mathbf{3 b}$ ). The 3D diagrams revealed the binding conformation and binding poses of the compounds at the catalytic site of alpha-amylase

(Figure 4c, 3d) were observed.
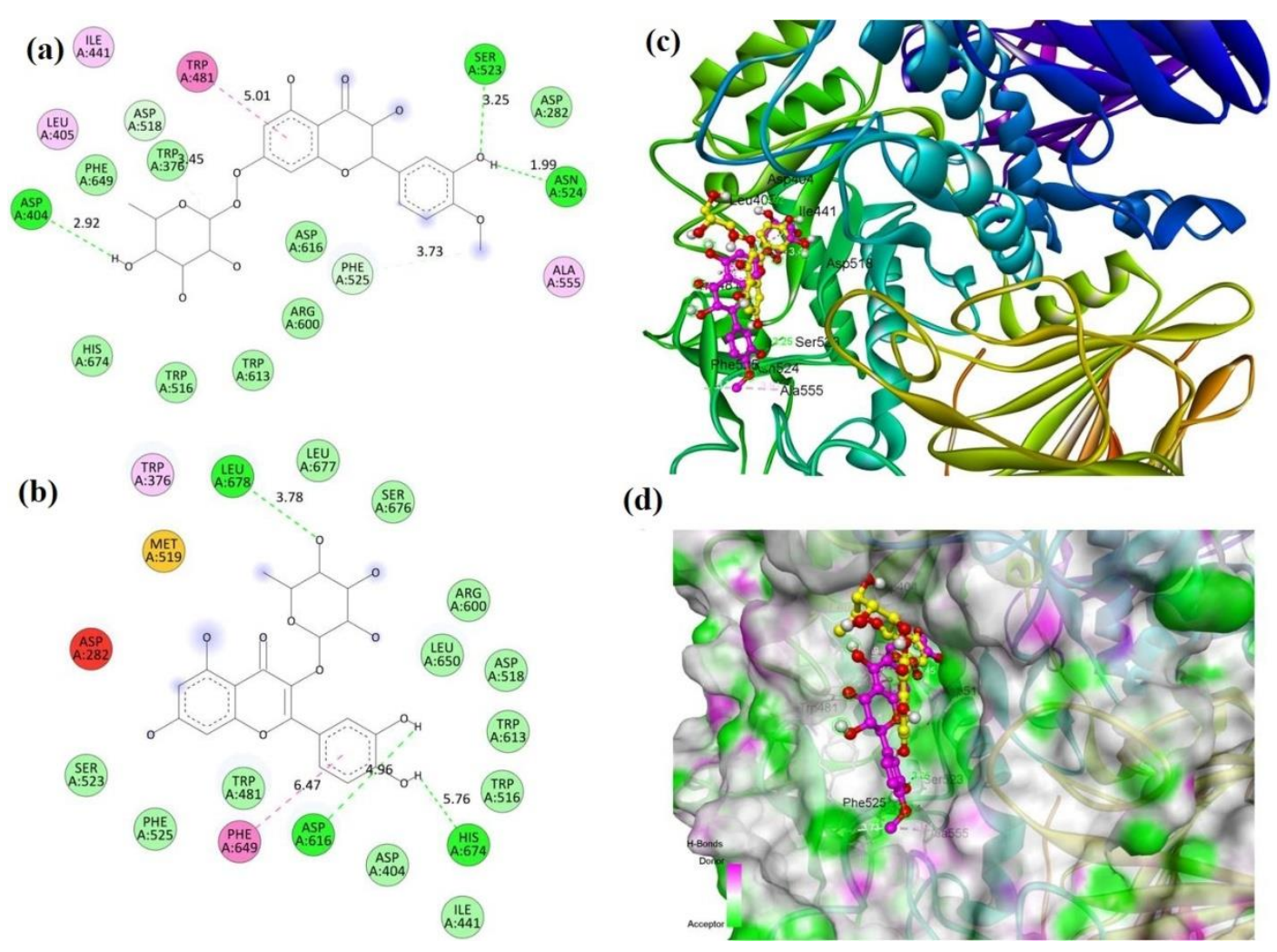

Figure 4. (a) 2D interactions between compound 1 and alpha-amylase, (b) 2D intercations between compound 2 and alpha-glucosidase showing hydrogen bonding and other non-covalent interactions with amino acid residues at the active site, (c) 3D representation of protein-ligand interactions showing binding conformation, (d) binding poses/ binding modes of both the compounds at the catalytic site of alpha-amylase.

Upon critical analysis of protein-ligand interactions, favourable binding orientations and/or binding modes of flavonoid molecules for both the alpha-glucosidase and alpha-amylase enzyme were evident. Both the compounds structurally represent glycosides of flavonones which are abundantly found in plant kingdom. The glycone part (sugar) i.e., the rhamnose moiety is similar in both the compounds, while the aglycone part (non-sugar bioactive principle, flavanone moiety) is dissimilar. In compound 1, it is 5,7,3'-trihydroxy-4-methoxyflavanone, whereas, it is $3,5,7,3^{\prime}, 4^{\prime}$-tetrahydroxy-4-methoxyflavanone i.e., quercetin in compound 2 . The aglycone i.e., the flavonoid moiety is a polyhydroxylated C6-C3-C6 tricyclic heteroaromatic system (phenylchromone) [10-12] with distinct structural features, particularly in terms of nature and pattern of ring substitutions. There is a close structural resemblance between these two isolated flavonoid glycosides. The basic flavonone skeleton along with hydroxylated/ methoxylated aromatic ring interacted predominantly with the active site residues of target protein molecules. Polar groups such as phenolic hydroxy groups and carbonyl 
moiety contributed significantly in protein-ligand interactions with the formation of hydrogen bonds. Apart from hydrogen bonding, other non-bonding intercations such as hydrophobic interations were also exist, but to a lesser extent. Aromatic bulky moieties chromone system and phenyl ring were mainly involved in non-polar hydrophobic intercations.

The human lysosomal alpha-glucosidase and pancreatic alpha-amylase enzymes play an important role in the digestion of dietary long-chain complex carbohydrates (breakdown of strach and disaccharides to glucose) and hence, their inhibition is believed to facilitate the reduction of post-prandial (post meal) blood glucose level in type 2 diabetes [13]. The traditional usefulness about the antidiabetic potential of $C$. dichotoma is mentioned in literature [2-4]. In our earlier studies, the antidiabetic activity of the methanolic bark extract of C. dichotoma has already been reported [4]. Moreover, literature suggest that the flavonoids content demonstrates antidiabetic efficacy of many plants [14-18]. Our docking study validates the antidiabetic claim about C. dichotoma reported in traditional medicines as well as in recent literature. Although the isolated phytocompounds are already established bioactive flavonoids with many scientific reports from past literature, their antidiabetic potential determined by in silico (molecular docking) methods with alpha-glucosidase and alpha amylase inhibitory activities has been reported for the first time. Our study may thus provide an avenue for further investigation with these bioflavonoids for their development as potent antidibaetic molecules with alpha-glucosidase and alpha-amylase inhibitory agents for the treatment of type 2 diabetes mellitus.

\subsection{ADMET}

Results of predicted ADMET (absorption, distribution, metabolism, excretion and toxicity) data showed that both the isolated compounds possess good solubility profile, which is in favour of their oral bioavailability. There is a prediction of poor intestinal absorption, while the compounds were predicted to be non-inhibitors of the cytochromess (CYP450) [19]. Poor intestinal absorption might be due to their limited oil/water partition coefficient $(\log \mathrm{P})$ values $(-1.64$ and -1.84$)$. CYP450 enzymes are largely involved in drug metabolism. Non-inhibition of CYP450 enzymes suggests that compounds do not suppress the metabolic fucntion of the enzymes. Inhibition can lead to increased bioavailability of compounds that normally undergo extensive first-pass elimination or to decreased elimination of compounds dependent on metabolism for systemic clearance. Compounds did not exhibit the property of blood brain barrier (BBB) penetration. It substantiates that the compounds are devoid of producing CNS toxicities. Furthermore, quercitrin (compound 2) was predicted to be a substrate to permeability of glycoprotein (p-gp), whereas the other flavonoid molecule (compound 1) did not show such property. Glycoprotein is responsible for the efflux of drug molecules out of the target cells [20]. A good drug candidate should not only have sufficient efficacy against the therapeutic target, but also show appropriate ADMET properties at a therapeutic dose. It is therefore inevitable to evalute the ADMET profile of drug-like molecules to avoid the failute of candidate drugs at the clinical stage of drug development [21]. 


\section{Materials and Methods}

\subsection{Collection of plant}

The barks of Cordia dichotoma Forst. were collected from the Duhai forest of Ghaziabad, Uttar Pradesh, India. The plant species was identified from National Institute of Science Communication and Information Resources, New Delhi, India. The voucher specimen (NISCAIR/RHMD/Consult/2012-13/2025/33) of the bark of Cordia dichotoma Forst. was submitted at the herbarium of the department for future reference.

\subsection{Preparation of methanolic bark extract}

The shade-dried barks of $C$. dichotoma were pulverized to a coarse powder and defatted using petroleum ether by cold maceration method [2] to remove fat, latex and non-polar compounds of high molecular weights. The defatted plant residues were then macerated succesively with methanol to obtain the desired extract [3, 4]. The collected extract was filtered through Whatman No. 1 filter paper. Rotary evaporator was used to concentrate the filtrate. The concentrated extract was preserved in refrigerator at $4{ }^{\circ} \mathrm{C}$ for further use. The percentage yield of the methanolic bark extract of $C$. dichotoma (MECD) was $7.11 \%$.

\subsection{Phytochemical analysis}

Chemical tests for the screening and detection of phytochemical constituents of the MECD were carried out using the standard procedures [22, 23].

\subsection{Isolation of phytocompounds}

The MECD was subjected to column chromatographic separation using silica gel (packed column, 100-200 mesh) and a glass column (6.0 $\times 3$ inch dimension) [6] for the isolation of bioactive phytoconstituents in pure form. The elution was carried out by gradient separation technique using the solvent system of n-hexane/ethyl acetate. The column was eluted successively with n-hexane:ethyl acetate in increasing order of polarity $(98: 2,95: 5,90: 10,80: 20,60: 40,50: 50,35: 65,30: 70,25: 75,20: 80$, and 100\%). The fractions collected were subjected to thin-layer chromatography (TLC) to check their homogeneity. Chromatographically identical fractions (having the same $R_{f}$ values) were combined together and concentrated. The concentrated fractions were purified by crystallization with methanol/benzene and confirmed by their sharp melting points.

\subsection{Identification of isolated compounds}

Ultraviolet (UV)-visible spectra were recorded on Shimadzu UV-1700 UV-visible spectrophotometer and the wave lengths of maximum absorption $\left(\lambda_{\max }, \mathrm{nm}\right)$ were reported. Infrared (IR) spectra were obtained on a Bruker Alpha Fourier Transform (FT-IR) spectrometer using KBR disc and reported in terms of frequency of absorption $\left(v_{\max }, \mathrm{cm}^{-1}\right) \cdot{ }^{1} \mathrm{H}$ and ${ }^{13} \mathrm{C}$ Nuclear Magnetic Resonance (NMR) spectra were recorded on Bruker Avance II 400 FT-NMR spectrometer at 400 and $100 \mathrm{MHz}$, respectively using tetramethylsilane (TMS) as an internal standard ( $\delta 0.00 \mathrm{ppm})$ and $\mathrm{CDCl}_{3}$ as a solvent. Mass spectra were obtained on a LC-MS Water 4000 ZQ instrument using electrospray 
ionization $\left(\mathrm{ES}^{+}\right)$. The $\mathrm{m} / \mathrm{z}$ values were recorded in the range of $\mathrm{m} / \mathrm{z}$ between $100-500$ and the $\mathrm{m} / \mathrm{z}$ values of the most intense molecular ion $[\mathrm{M}]+$ peak were considered. Melting points were determined on an electric melting point apparatus (JSGW, Model 3046).

\subsection{Molecular docking}

The X-ray crystal structure of proteins, viz., human lysosomal acid alpha-glucosidase (PDB ID: 5NN8) and human pancreatic alpha-amylase (PDB ID: 1B2Y) were reposited by Roig-zamboni et al. [24] and Nahoun et al. [25] having resolution of $2.45 \AA$ and $3.20 \AA$, respectively were retrieved from the RCSB protein data bank (http://www.rcsb.org/).

Prior to docking, The docking was performed in the AutoDock Vina software [26] in accordance with the standard procedure. The protein crystal structure was prepared prio to the docking process. Hydrogen atoms were added to the protein structure, and all ionizable residues were set at their default protonation at $\mathrm{pH} \quad 7.4$. The active site coordinates were determined with the dimensions of $x=-15.941, y=-37.643, z=92.912$ for $5 \mathrm{NN} 8$ and $x=22.116, y=4.749, z=45.878$ for 1B2Y, and, a grid box with radius of $25 \times 25$ x $25 \mathrm{~A}^{3}$ was generated for both the proteins. Similarly, the ligands were prepared and energy minimized using Chem3D 17.0 software. During the docking process, the receptor was rigidly held, while the ligands were allowed to flex during the refinement. Binding energies of docking were recorded and analyzed. The best docked poses and binding modes of protein-ligand interactions were obtained using the Discovery Studio visualizer.

\subsection{ADMET prediction}

Predictive ADMET (pharmacokinetics) parameters were studied using web-based Swiss ADME tool developed by Daina et al. [27]. Solubility, intestinal absorption, oil/water partition coefficient $(\log \mathrm{P}), \mathrm{CYP} 450$ inhibition, blood brain barrier penetration, and p-gp substrate were predicted [28].

\section{Conclusions}

This study reports two bioactive flavonoids, viz., 3,5,7,3', $4^{\prime}$-tetrahydroxy-4-methoxyflavanone-3-O-L-rhamnopyranoside and 5,7,3'-trihydroxy-4-methoxyflavanone-7-O-L-rhamnopyranoside (Quercitrin) isolated and identified from the methanolic bark extract Cordia dichotoma Forst. Molecular docking study investigates the antidiabetic potential of the isolated flavonoids against human lysosomal acid alpha-glucosidase and human pancreatic alpha-amylase enzymes. Predictive ADMET study demonstrates acceptable pharmacokinetics of the isolated compounds. In silico study needs to be further validated by in vitro and in vivo experimental assays in order to confirm the antidiabetic effectiveness for the flavonoids reported herein. Our study may thus provide an avenue for further investigation with these bioflavonoids for their development as potent antidibaetic molecules with 
alpha-glucosidase and alpha-amylase inhibitory agents for the treatment of type 2 diabetes mellitus.

Author Contributions: Conceptualization, N.H. and B.B.K.; methodology, N.H.; software, I.C.; validation, I.C. and M.R.; formal analysis, M.R. and E.I.A.; investigation, N.H. and I.C.; resources, B.B.K. and I.C.; data curation, M.R., I.C. and S.J.K.; writing-original draft preparation, M.R. and E.I.A.; writing - review and editing, E.I.A. and S.J.K.; visualization, E.I.A.; supervision, B.B.K; project administration, B.B.K.; funding acquisition, S.J.K., K.K.S., S.B. and R.K.S. All authors have read and agreed to the published version of the manuscript.

Funding: This research received no external funding.

Data Availability Statement: Additional data will be made available on request.

Acknowledgments: Authors gratefully acknowledge the TÜBITAK (The Scientific and Technological Research Council of Turkey), ULAKBIMM (Turkish Academic Network and Information Centre), High Performance and Grid, Computing Centre (TRUBA resources), Turkey for providing necessary facilities for performing the computational studies. Authors extend their sincere thanks to Dr. Sagariaka Chandra for her needful help towards editing the images incorporated in the manuscript.

Conflicts of Interest: The authors declare no conflict of interest.

\section{References}

1. Jamkhande, P.G.; Barde, S.R.; Patwekar, S.L.; Tidke. P.S. Plant profile, phytochemistry and pharmacology of Cordia dichotoma (Indian cherry): A review. Asian Pac. J. Trop. Biomed. 2013, 3, 1009-1012.

2. Hussain, N.; Kakoti, B.B.; Rudrapal, M.; Junejo, J.A.; Laskar, M.A.; Lal. M.; Sarwa, K.K. Anticancer and Antioxidant Activities of Cordia dichotoma Forst. Int. J. Green. Pharm. 2020, 14, 265-273.

3. Hussain, N.; Kakoti, B.B.; Rudrapal, M.; Sarwa, K.K. Anti-inflammatory and Antioxidant Activities of Cordia dichotoma Forst. Bark. Biomed. Pharmacol. 2020, 13, 2093-2099.

4. Hussain, N.; Kakoti, B.B.; Rudrapal, M.; Rahman, Z.; Rahman, M.; Chutia, D.; Sarwa, K.K. Antidiabetic Activity of the bark of Indian Cherry, Cordia dichotoma. Biosci. Biotech. Res. Comm. 2020,13, 2211-2216.

5. Ragasa, C.Y.; EbajoJr, V.D.; Mariquit, M.; Mandia, E.H.; Tan, M.C.S.; Brkljača, R.; Urban, S. Chemical constituents of Cordia dichotoma G. Forst. J. Appl. Pharm. Sci. 2015, 5, 16-21.

6. Junejo, J.A.; Rudrapal, M.; Mohammed, A.; Zaman, K. New flavonoid with antidiabetic potential from Tetrastigma angustifolia (Roxb.) Deb leaves. Brazilian J. Pharm. Sci. 2020, 56, e18806.

7. Junejo, J.A.; Mondal, P.; Rudrapal, M.; Zaman, K. Antidiabetic assessment of the hydro-alcoholicleaf extracts of the plant Tetrastigma angustifolia (Roxb.), a traditionally used North-Eastern Indian vegetable. Biomed. Pharmacol. J. 2014, 7, 635-644.

8. Junejo, JA.; Gogoi, G.; Islam, J.; Rudrapal, M.; Mondal, P.; Hazarika, H.; Zaman, K. Exploration ofantioxidant, antidiabetic and hepatoprotective activity of Diplazium esculentum, a wild edible plant from North Eastern region of India. Future J. Pharm. Sci. 2018, 4, 93-101.

9. Kumar, S.; Kaushik, A.; Narasimhan, B.; Shah, S.A.; Lim, S.M.; Ramasamy, K.; Mani, V. Molecular docking, synthesis and biological significance of pyrimidine analogues as prospective antimicrobial and antiproliferative agents. BMC Chem. 2019, 13, 1-7. 
10. Wen, W.; Alseekh, S.; Fernie, A.R. Conservation and diversification of flavonoid metabolism in the plant kingdom. Curr. Opin. Plant Biol. 2020, 55, 100-108.

11. Arora, S.; Itankar, P. Extraction, isolation and identification of flavonoid from Chenopodium album aerial parts. J. Trad. Comp. Med. 2018, 8, 476-482.

12. Kishore, N.; Twilley, D.; Blom van Staden, A.; Verma, P.; Singh. B.; Cardinali, G.; Lall, N. Isolation of flavonoids and flavonoid glycosides from Myrsine africana and their inhibitory activities against mushroom tyrosinase. J. Nat. Prod. 2018, 81, 49-56.

13. Tundis, R.; Loizzo, M.R.; Menichini, F. Natural products as $\alpha$-amylase and $\alpha$-glucosidase inhibitors and their hypoglycaemic potential in the treatment of diabetes: an update. Mini Rev. Med. Chem. 2010, 10, 315-31.

14. Junejo, J.A.; Zaman, K.; Rudrapal, M.; Hussain, N. Antidiabetic and Antioxidant Activity of Hydro-alcoholic Extract of Oxalis debilis Kunth. Leaves in Experimental Rats. Biosci. Biotech. Res. Comm. 2020, 13, 860-867.

15. Junejo, J.A.; Rudrapal, M.; Zaman, K. Antidiabetic activity of Carallia brachiata Lour. Leaves hydro-alcoholic extract (HAE) with antioxidant potential in diabetic rats. Indian J. Nat. Prod. Resour. 2020, 11, 18-29.

16. Junejo, J.A.; Rudrapal, M.; Nainwal, L.M.; Zaman, K. Antidiabetic activity of hydro-alcoholic stem bark extract of Callicarpa arborea Roxb. with antioxidant potential in diabetic rats. Biomed. Pharmacother. 2017, 95, 84-94.

17. Rashed, K.N.; Butnariu, M. Isolation and antimicrobial and antioxidant evaluation of bioactive compounds from Eriobotrya japonica stem. Adv. Pharm. Bull. 2014, 4, 75-81.

18. Conforti, F.; Statti, G.A.; Tundis, R.; Menichini, F.; Houghton, P. Antioxidant activity of methanolic extract of Hypericum triquetrifolium Turra aerial part. Fitoterapia. 2002, 73, $479-483$.

19. Lynch, T.; Price, A.L. The effect of cytochrome P450 metabolism on drug response, interactions, and adverse effects. Am. Fam. Physician. 2007, 76, 391-396.

20. Feng, B.; Mills, J.B.; Davidson, R.E.; Mireles, R.J.; Janiszewski, J.S.; Troutman. M.D.; deMorais, S.M. In vitro P-glycoprotein assays to predict the in vivo interactions of P-glycoprotein with drugs in the central nervous system. Drug Metab. Dispos. 2008, 36, 268-275.

21. Isyaku, Y.; Uzairu, A.; Uba, S. Computational studies of a series of 2-substituted phenyl-2-oxo-,2-hydroxyl-and 2-acylloxyethylsulfonamides as potent anti-fungal agents. Heliyon. 2020, 6, e03724.

22. Onah, O.E.; Babangida,K.J. Phytochemical Investigation and Antimicrobial Activity of Hexane, Ethyl Acetate and Methanol Fractions from Stem Bark of Icacina trichantha Oliv (Icacinaceae). J. Chem. En. Sci. A.2020, 7, 7-12.

23. Jigna, P.;Sumitra, C. Phytochemical screening of some plants from western region of India. Plan. Arch. 2008, 8, 657-662.

24. Roig-Zamboni, V.; Cobucci-Ponzano, B.; Iacono, R.; Ferrara, M.C.; Germany, S.; Bourne, Y.; Sulzenbacher,G. Structure of human lysosomal acid $\alpha$-glucosidase-a guide for the treatment of Pompe disease. Nat. Commun. 2017, 8, 1-10.

25. Nahoum, V.; Roux, G.; Anton, V.; Rougé, P.; Puigserver, A.; Bischoff, H.; Payan, F. Crystal structures of human pancreatic $\alpha$-amylase in complex with carbohydrate and proteinaceous inhibitors. Biochem. J. 2000, 346, 201-208. 
26. Trott, O.; Olson, A.J. AutoDockVina: improving the speed and accuracy of docking with a new scoring function, efficient optimization, and multi threading. J. Comput. Chem., 2010, 31, 455-461.

27. Daina, A.; Michielin, O.; Zoete, V. Swiss ADME: a free web tool to evaluate pharmacokinetics, drug-likeness and medicinal chemistry friendliness of small molecules. Sci. Rep. 2017, 7, 1-13.

28. Kato-Schwartz, C.G.; deSá-Nakanishi, A.B.; Guidi, A.C.; Gonçalves, D.A.; Bueno, F.G.; Zani, B.P.M.; Peralta, R.M. Carbohydrate digestive enzymes are inhibited by Poincianellapluviosa stem bark extract: relevance on type 2 diabetes treatment. Clin. Phytosci. 2020, 6, 1-11. 